\title{
Use of Resonance Parameters of Air-intakes for the Identification of Aircrafts
}

\author{
Janic Chauveau, Nicole de Beaucoudrey and Joseph Saillard \\ IREENA Laboratory, University of Nantes
}

France

\section{Introduction}

Since the development of radar systems, extensive researches have been conducted on the detection and the identification of radar targets. From the scattered electromagnetic field, the aim is to detect and characterize radar targets. In a military context, these targets try to get stealthy to assure their security. This can be provided by using composite materials which absorb electromagnetic waves in usual radar frequency bands. Consequently, studies are involved in lower frequencies. These lower frequency bands correspond to the resonance region for object dimensions of the same order as electromagnetic wavelengths. Therefore, the energy scattered by the target significantly fluctuates and resonance phenomena clearly appear in this region.

Extensive studies have been performed to extract these resonances, mainly the Singularity Expansion Method (SEM) introduced by Baum (Baum, 1976), (Baum, 1991). For years, the SEM is used to characterize the electromagnetic response of structures in both the time and the frequency domains. The SEM was inspired by observing that typical transient temporal responses of various scatterers (e.g. aircrafts, antennas ...) behave as a combination of exponentially damped sinusoids. Such temporal damped sinusoids correspond, in the complex frequency domain, to complex conjugate poles called "natural" poles. The knowledge of these singularities is an useful information for the discrimination of radar targets and it can be used for different purposes of recognition and identification. For example, the E-pulse technique consists in synthesizing "extinction-pulses" signals from natural poles of an expected target, then in convolving them with the measured late-time transient response of a target under test, what leads to zero responses if both targets match (Chen et al., 1986), (Rothwell et al., 1987), (Toribio et al., 2003). In fact, the mapping of these natural poles in Cartesian complex plane behaves as an identity card enabling to recognize the detected target by comparison with a data base of mapping of poles, created before experiments for a set of possible targets. Moreover, the information contained in natural poles can give some indications on the general shape, the nature and the constitution of the illuminated target.

Among radar targets identification problems, the scattering characterization of aircrafts is a relevant topic. Indeed, jet-engine inlets give a very significant contribution to the overall Radar Cross Section (RCS) of an airplane structure. More generally, apertures such as inlets, open ducts and air-intakes can be used for aircraft identification. Thus, numerous studies on the scattering from open cavities are found in the literature. The reader is invited to read the 
paper of Anastassiu (Anastassiu, 2003), which presents a quite extensive review of methods used to calculate the RCS of such open structures (more than 150 references).

Particularly, when illuminated in a suitable frequency band, an aperture in a radar target body can give access to high-Q internal resonances. Hence the use of natural frequencies of resonance, mainly internal ones, is a relevant basis for open targets identification.

In section 2, we first explain what are the poles corresponding to resonance phenomena and we present the extraction of these natural poles from the simulated transfer function of a target. Using examples of canonical targets (a sphere and a dipole), we consider resonance parameters in the usual Cartesian representation in the complex plane, with real part $\sigma$ and imaginary part $\omega$, but also in a new representation with quality factor $Q$ and natural pulsation of resonance $\omega_{0}$. We then introduce the use of these resonance parameters to characterize objects. Afterwards, we extend our study to resonances of targets with apertures, which can give access to internal resonances. In section 3, we first choose the simple example of a perfectly conducting (PC) rectangular open cavity to show how resonance parameters depend on object dimensions and permit to distinguish internal and external resonances. Finally, in section 4, we present a more realistic example in the case of a simulated aircraft with air-intakes, in order to show how to take advantage of internal resonances phenomena of air-intakes for the identification of aircrafts.

\section{Resonance parameters of a radar target}

A radar target is illuminated in far field by an incident broadband plane wave including resonant frequencies of the target. Consequently, induced resonances occur at these particular frequencies. In the frequency domain, the scattered-field transfer function $\mathrm{H}$ is given by the ratio of the scattered field to the incident field, for each frequency. In the time domain, the scattered transient response is composed of two successive parts. First, the impulsive part, $h_{\mathrm{E}}(\mathrm{t})$, corresponding to the early time, comes from the direct reflection of the incident wave on the object surface. In general, for a monostatic configuration, in free space, this forced part is of duration $0<\mathrm{t} \leq \mathrm{T}_{\mathrm{L}}=2 \mathrm{D} / \mathrm{c}$, where $\mathrm{D}$ is the greatest dimension of the target and $c$ the celerity of light (Kennaugh \& Moffatt, 1965). Next, during the late time $\left(t \geq T_{L}\right)$, the oscillating part, $h_{L}(t)$, is due to resonance phenomena of the target. These resonances have two origins (Chen, 1998): resonances occurring outside the object are called "external resonances" and correspond to surface creeping waves. Conversely, resonances occurring inside the object are called "internal resonances" and correspond to potential cavity waves. In the case of a perfectly conducting closed target, only external resonances occur. The resonant behaviour of the late time is characteristic of the studied target and can be used to define a method of identification.

\subsection{Extraction of natural poles}

The Singularity Expansion Method (SEM) (Baum, 1976), (Baum, 1991) provides a convenient methodology, describing the late time response of various scatterers as a finite sum of exponentially damped sinusoids

$$
\mathrm{h}_{\mathrm{L}}(\mathrm{t}) \approx \sum_{\mathrm{m}=1}^{\mathrm{M}} 2\left|\mathrm{R}_{\mathrm{m}}\right| \exp \left(\sigma_{\mathrm{m}} \mathrm{t}\right) \cos \left(\omega_{\mathrm{m}} \mathrm{t}+\varphi_{\mathrm{m}}\right)
$$


Conversely, the Laplace transform of equation (1) gives the scattered-field transfer function $\mathrm{H}(\mathrm{s})$ corresponding to the sum of pairs of complex conjugate poles in the complex frequency plane

$$
\mathrm{H}(\mathrm{s}) \approx \sum_{\mathrm{m}=1}^{\mathrm{M}}\left(\frac{\mathrm{R}_{\mathrm{m}}}{\mathrm{s}-\mathrm{s}_{\mathrm{m}}}+\frac{\mathrm{R}_{\mathrm{m}}^{*}}{\mathrm{~s}-\mathrm{s}_{\mathrm{m}}^{*}}\right)
$$

where $s=\sigma+j \omega$ is the complex variable in the Laplace plane. $M$ is the total number of modes of the series. For the $\mathrm{m}^{\text {th }}$ singularity, $\mathrm{R}_{\mathrm{m}}$ is the residue associated to each natural pole $s_{\mathrm{m}}=\sigma_{\mathrm{m}}+j \omega_{\mathrm{m}}\left(R_{\mathrm{m}}{ }^{*}\right.$ and $s_{\mathrm{m}}{ }^{*}$ are complex conjugate of $R_{\mathrm{m}}$ and $\left.s_{\mathrm{m}}\right)$. The imaginary part, $\omega_{\mathrm{m}}$, is the resonance pulsation. The real part, $\sigma_{\mathrm{m}}$, is negative, indeed corresponding to a damping due to radiation losses and losses on the surface and, eventually, inside dielectric targets. In the following, $\left|\sigma_{\mathrm{m}}\right|$ is named the damping coefficient.

In order to choose a technique of extraction of such singularities, we present here a brief state of the art of existing methods. In time domain, Prony proposed as soon as 1795 (Prony, 1795) to model transient responses as a sum of damped sinusoids (equation (1)). Concerning the characterization of targets, this led to the development of algorithms for finding natural poles and their associated residues, by studying either the impulse response of targets in time domain or their transfer function in frequency domain (Baum, 1991), (Sarkar \& Pereira, 1995), (Kumaresan, 1990).

In time domain, the most popular algorithms of poles extraction are based on Prony's methods: The original method of Prony (Prony, 1795), very sensitive to noise in measured data, has been later improved in Least Square-Prony (LS-Prony) (Householder, 1950) and Total Least Square-Prony (TLS-Prony) (Rahman \& Yu, 1987) methods, by using Singular Value Decomposition (SVD) (Hua \& Sarkar, 1991). However, in the case of a low signal-tonoise environment, only a few modes can be reliably extracted by this inherently illconditioned algorithm. More recently developed, the Matrix Pencil Method (MPM) (Sarkar \& Pereira, 1995) is more robust to noise in the sampled data, it has a lower variation of estimates of parameters than Prony's methods and it is also computationally more efficient. Moreover, the use of the Half Fourier Transform better separates the early and the late time responses (Jang et al., 2004), through a precise determination of the beginning of the late time $\mathrm{T}_{\mathrm{L}}$.

An alternative approach to time domain estimators, such as Prony's and MPM methods, consists in extracting poles and residues directly from the frequency data set. Frequency domain methods are advantageous when measurements are performed in the frequency domain. Thus one does not need to perform an inverse Fourier transform to obtain time domain response. Cauchy showed in 1821 that it is possible to approximate a function by a rational function approximation (Cauchy, 1821). The original frequency domain method of poles extraction is based on this approximation for the transfer function (Adve et al., 1997), (Kottapalli et al., 1991). Many papers present and compare these various techniques of poles extraction, e.g. in signal processing (Kumaresan, 1990), (Kumaresan, 1990) as well as in object scattering (Tesche, 1973), (Moffatt \& Shubert, 1977), (Licul, 2004), (Li \& Liang, 2004). Whereas temporal methods solve polynomial equations of order equal to the number of existing poles, frequency domain methods require to solve higher order polynomial equations than the number of poles. Consequently, frequency domain methods are not suitable when this number of poles is very large. However, in scattering problems, these 
methods are advantageous in comparison with temporal methods because they avoid the choice of the beginning of the late time response.

For all the examples presented in this paper, we can use any of these existing methods to extract poles. We choose to use numerical data obtained with an electromagnetic simulation software, which is based on the Method of Moments (FEKO) and gives the scattered field at different frequencies. Consequently, we choose a frequency domain method (Cauchy, 1821), (Moffatt \& Shubert, 1977) and (Kumaresan, 1990).

As an example, we present in figure 1 the modulus of the scattered-field transfer function $\mathrm{H}(\omega)$ of two perfectly conducting canonical targets: a dipole of length $\mathrm{L}=0.15 \mathrm{~m}$ and aspectratio $\mathrm{L} / \mathrm{D}=150$ where $\mathrm{D}$ is the diameter, and a sphere of diameter $\mathrm{D}=0.15 \mathrm{~m}$. Both targets are studied in free-space, in the frequency range $[50 \mathrm{MHz}-12.8 \mathrm{GHz}]$ which contains the resonance region of the studied targets (the pulsation range is $\left[3.10^{8} \mathrm{rad} / \mathrm{sec}-8.10^{10}\right.$ $\mathrm{rad} / \mathrm{sec}])$. We note that for a very resonant object, such as the dipole, resonance peaks are narrow and clearly appear in the response $|\mathrm{H}(\omega)|$, what is not the case for a less resonant object as the sphere. For efficient target characterization, it is important to define a frequency range adapted to scatterer dimensions, such as it really contains not only the fundamental pulsation of resonance but also further harmonic pulsations (Baum, 1991).

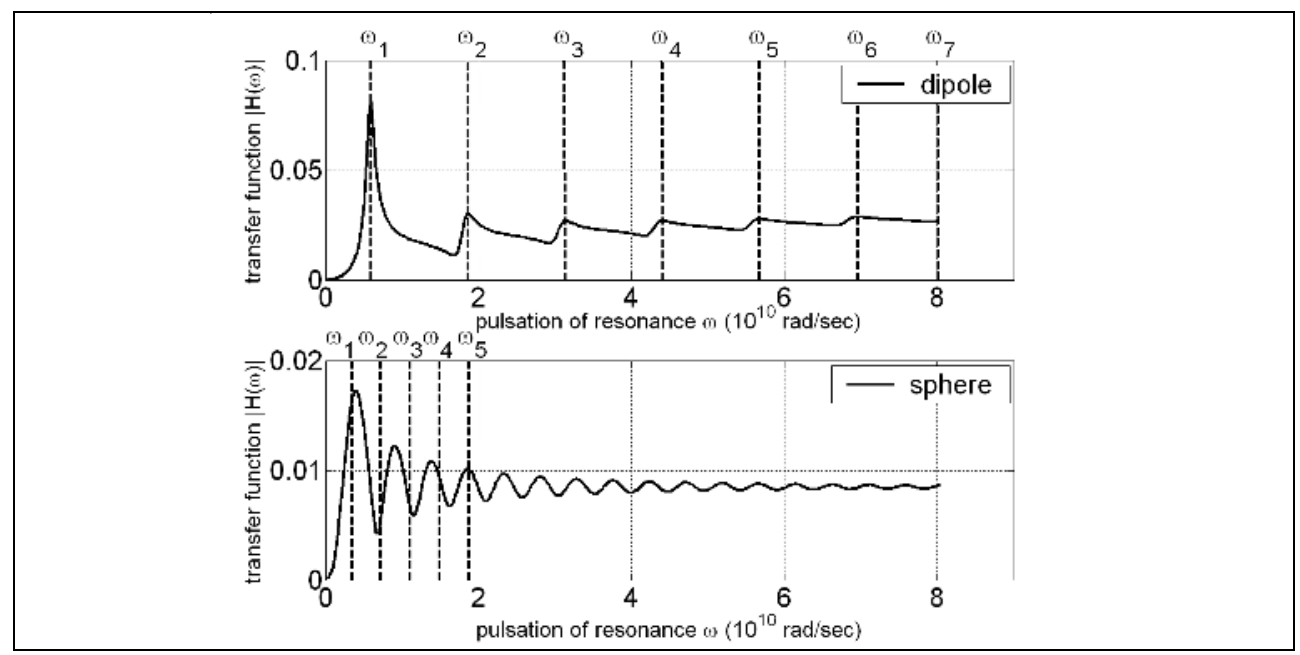

Fig. 1. Modulus of the transfer function $H(\omega)$ of the dipole (upper) and the sphere (lower). 256 samples, monostatic configuration.

In order to extract poles of resonance, the Cauchy's method (Cauchy, 1821) is applied for approximating the transfer function, $\mathrm{H}$, by a ratio of two complex polynomials (Tesche, 1973), (Moffatt \& Shubert, 1977), (Licul, 2004), (Li \& Liang, 2004). The zeros of the denominator polynomial, $\mathrm{B}(\mathrm{s})$, are the poles of $\mathrm{H}(\mathrm{s})$. We obtain

$$
\mathrm{H}(\mathrm{s}) \approx \frac{\mathrm{A}(\mathrm{s})}{\mathrm{B}(\mathrm{s})} \approx \sum_{\mathrm{n}=1}^{\mathrm{N}} \frac{\mathrm{R}_{\mathrm{n}}}{\mathrm{s}-\mathrm{s}_{\mathrm{n}}}
$$

where $\mathrm{N}$ is the total number of singularities of the development and $R_{n}$ is the residue associated to each pole $\mathrm{s}_{\mathrm{n}}$. 
Among these $\mathrm{N}$ poles, we expect to get the $\mathrm{M}$ pairs of poles corresponding to resonances, called "natural" poles. As stated in (2), they are complex conjugate, with negative real part $\sigma_{\mathrm{m}}$, and should be independent of the form of the fitting function and the order $\mathrm{N}$ of the rational function. It is assumed that all natural poles are simple (Baum, 1976). In fact, we find not only these natural poles but also "parasitical" poles, which are not complex conjugate by pair and/or have a positive real part. Some of theses parasitical poles correspond to the early time effects, which cannot be represented by exponentially damped sinusoids. Moreover, these parasitical poles depend of the order $\mathrm{N}$ in (3). To be sure to get the whole set of natural poles, we choose a high value of the order $\mathrm{N}(\mathrm{N}=50$ for instance). In order to separate the $2 \mathrm{M}$ natural poles and the $\mathrm{N}-2 \mathrm{M}$ parasitical poles, we vary the value of $\mathrm{N}$ of some units $(\mathrm{N}=50 \pm 2)$. Consequently, extracted poles are natural ones not only if they are complex conjugate by pair and have a negative real part, but also if their value is stable when $\mathrm{N}$ varies. In our examples, we find $2 \mathrm{M}=14$ (7 resonances) for the studied dipole and $2 \mathrm{M}=10$ ( 5 resonances) for the sphere.

In figure 2, we plot the mapping of natural poles for the studied targets, in one quarter of the complex plane $(\sigma<0$ and $\omega>0)$, because poles have a negative real part and are complex conjugate. Indeed, for canonical targets (sphere, cylinder, dipole ...), poles are distributed over branches joining the fundamental pulsation of resonance, $\omega_{1}$, and harmonic pulsations (Chen, 1998) (Chauveau, 2007-a). For a very resonant target as a dipole, we can notice that resonance peaks of $|\mathrm{H}(\omega)|$ occur at pulsations of resonance $\omega_{\mathrm{m}}$ (figure 1 - upper). However, in the case of a weakly resonant target as the sphere, peaks of resonance, corresponding to pulsation of resonance, $\omega_{\mathrm{m}}$, overlay and cannot be distinguished in the modulus of the transfer function $|\mathrm{H}(\omega)|$ (Figure 1 - lower). Indeed, low resonant targets have natural poles with high value of damping factor, $\left|\sigma_{\mathrm{m}}\right|$, corresponding to wide peaks. Moreover, because of this low resonant behaviour, natural poles of high order $\left(s_{m}>s_{5}\right.$ for the studied sphere) become difficult to obtain. Only the fundamental pole and some harmonic poles can be obtained. On the contrary, for the dipole, we succeed in extracting all poles existing in the studied pulsation range $\left[\omega_{\min } ; \omega_{\max }\right]$.

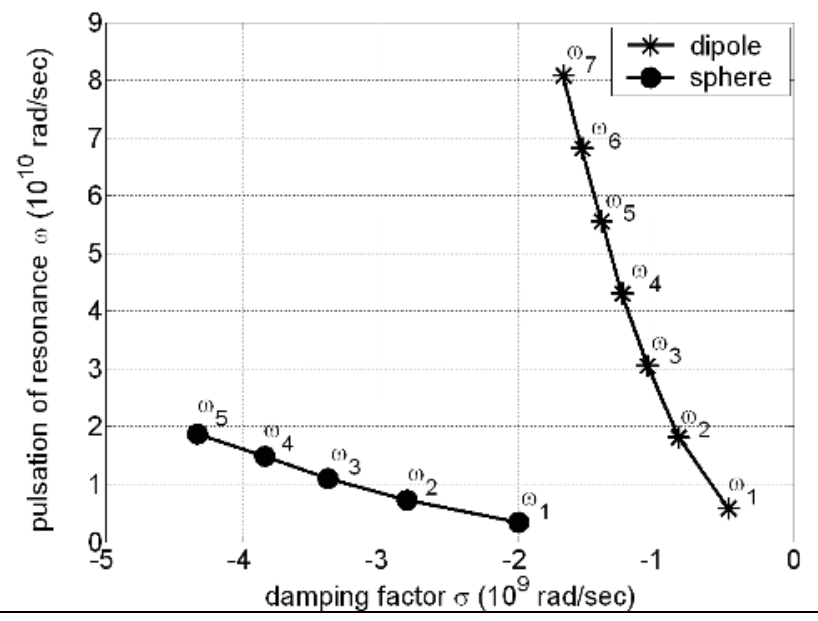

Fig. 2. Mapping of natural poles extracted from $\mathrm{H}(\omega)$ of figure 1 in the complex plane $\{\sigma, \omega\}$, $(\mathrm{M}=7$ for the dipole, $\mathrm{M}=5$ for the sphere). 
The main advantage of using such natural poles is that only 3 parameters $\left\{\omega_{\mathrm{m}} ; \sigma_{\mathrm{m}} ; R_{\mathrm{m}}\right\}$ are required to define each resonance mode. Moreover, in a homogeneous medium, the mapping of natural poles $\left\{\sigma_{\mathrm{m}} ; \omega_{\mathrm{m}}\right\}$ is independent of the target orientation relatively to the excitation (Berni, 1975) and can be used as a discriminatory of targets. Furthermore, among the whole set of these possible poles, only a few of them appreciably contribute to the target response and are thus sufficient to characterize a radar target (Chauveau, 2007-a). In general, the selected poles are those which are close to the vertical axis.

In order to show that the representation of resonances with natural poles is an efficient way to characterize the resonance behaviour of targets, we compare the time domain responses, $h(t)$, calculated by inverse Fourier transform of $H(\omega)$ and $h_{\text {rec }}(t)$, reconstructed using (1) from $\mathrm{M}$ pairs of natural poles. In figure 3, for the dipole, both temporal responses are almost identical, in the late time domain corresponding to resonance phenomena. This comparison is performed in the time domain $\left(t>T_{L}\right)$ and not in the frequency domain, because the early time effect is spread all over the frequency band of the initial response, forbidding any comparison between initial and reconstructed frequency responses.

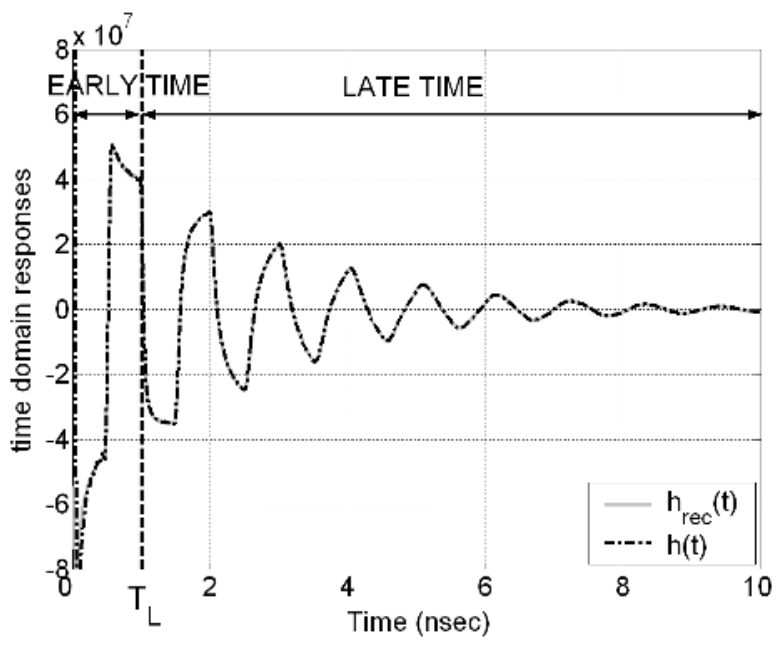

Fig. 3. Time domain response $h(t)$ compared with $h_{\text {rec }}(t)$ reconstructed with $M=7$ natural pairs of poles of Fig. 2 (dipole).

To quantitatively measure the difference between $h(t)$ and $h_{\text {rec }}(t)$, we used the normalised mean square error

$$
\text { MSE }=\sqrt{\sum_{\mathrm{t}}\left|\mathrm{h}(\mathrm{t})-\mathrm{h}_{\mathrm{rec}}(\mathrm{t})\right|^{2}} / \sum_{\mathrm{t}}|\mathrm{h}(\mathrm{t})|
$$

both sums being calculated for $t>2 \mathrm{~T}_{\mathrm{L}}$, in order to be sure that the resonances are well established. In fact, $\mathrm{T}_{\mathrm{L}}$ can be precisely determined using the Half Fourier Transform (Jang et al., 2004). For the dipole response plotted in figure 3, we get a MSE of $10^{-4}$, with $M=7$ pairs of poles. For the studied sphere, we get a MSE of $5.10^{-3}$, with $M=5$ pairs of poles. 


\subsection{Representation of natural poles with the quality factor and the natural pulsation of} resonance

In (Chauveau, 2007-b), we propose to represent a natural pole $\left(s_{m}=\sigma_{m}+j \omega_{m}\right)$ not only in Cartesian coordinates, $\left\{\sigma_{\mathrm{m}} ; \omega_{\mathrm{m}}\right\}$, but also in the form $\left\{\omega_{0, \mathrm{~m}} ; \mathrm{Q}_{\mathrm{m}}\right\}$ with the natural pulsation of resonance, $\omega_{0, m}$, and the quality factor, $Q_{m}$.
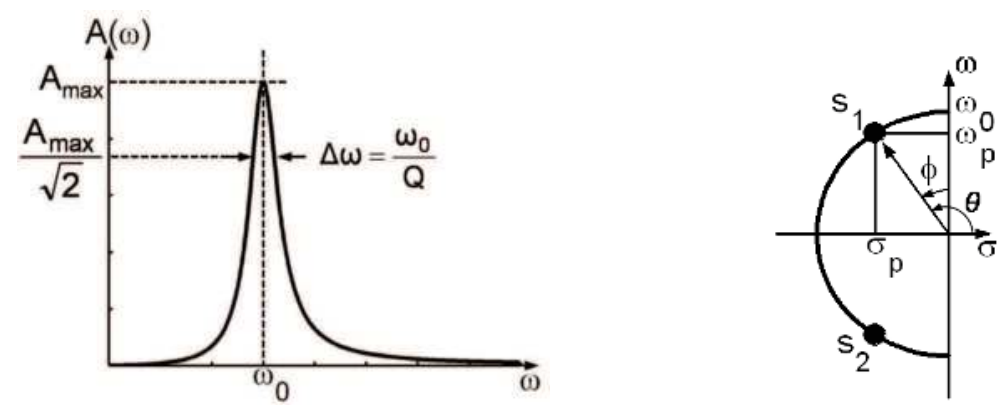

Fig. 4. Resonator: transfer function (a) and representation of poles in complex plane (b).

The transfer function of a resonator, mechanical as well as electrical, with a natural pulsation of resonance $\omega_{0}$ and a quality factor $Q$, is given by (figure 4-a)

$$
\mathrm{A}(\omega)=\frac{\mathrm{A}_{\max }}{1+j \mathrm{Q}\left(\frac{\omega}{\omega_{0}}-\frac{\omega_{0}}{\omega}\right)}
$$

In order to determine the poles of such resonator, we replace, in equation (5), j $\omega$ by s, complex variable in the Laplace plane. Thus, the s-plane transfer function is

$$
\begin{aligned}
A(s) & =A_{\max } \frac{s\left(\omega_{0} / Q\right)}{s^{2}+s \omega_{0} / Q+\omega_{0}^{2}} \\
& =A_{\max } \frac{\omega_{0}}{Q} \frac{\mathrm{s}}{\left(s-s_{1}\right)\left(s-s_{2}\right)}=\frac{r_{1}}{\left(s-s_{1}\right)}+\frac{r_{2}}{\left(s-s_{2}\right)}
\end{aligned}
$$

with $s_{1}$ and $s_{2}$, the two roots of the denominator of $\mathrm{A}(\mathrm{s})$

$$
s_{1,2}=-\frac{\omega_{0}}{2 Q} \pm j \omega_{0} \sqrt{1-\left(\frac{1}{2 Q}\right)^{2}}
$$

For $\mathrm{Q}>1 / 2$, the two poles $\mathrm{s}_{1,2}$ are complex conjugate, with respective residue $\mathrm{r}_{1,2}$

$$
\mathrm{r}_{1}=\mathrm{r}_{2}^{*}=\mathrm{A}_{\max } \frac{\omega_{0}}{\mathrm{Q}} \frac{\mathrm{s}_{1}}{\left(\mathrm{~s}_{1}-\mathrm{s}_{2}\right)}
$$

In the complex plane (figure 4-b), the poles, $s_{1,2}=\sigma_{p} \pm j \omega_{p}$, are located on the half-circle of radius equal to the natural pulsation of resonance, $\omega_{0}$. The real part of poles (damping factor) $\sigma_{p}$ and the imaginary part (damped pulsation) $\omega_{p}$ are given by 


$$
\sigma_{\mathrm{p}}=-\frac{\omega_{0}}{2 \mathrm{Q}}=-\frac{\Delta \omega}{2} \quad \omega_{\mathrm{p}}=\omega_{0} \sqrt{1-\left(\frac{1}{2 \mathrm{Q}}\right)^{2}}
$$

When $Q$ value is high, $\omega_{\mathrm{p}}$ is very close to $\omega_{0}$. Consequently, the damped pulsation $\omega_{\mathrm{P}}$ is often improperly used instead of the natural pulsation $\omega_{0}$.

In polar coordinates, we get: $s_{1,2}=\omega_{0} \exp \pm \mathrm{i} \theta$, with $\omega_{0}$ the modulus and $\theta$ the angle of $s_{1,2}$. We prefer to use a modified polar representation in the half complex plane $(\sigma<0):\left\{\omega_{0} ; \Phi\right\}$ where $\Phi=\theta-\Pi / 2$ is the angle between the pole direction and the imaginary axis $\omega$. We have

$$
2 \sin \Phi=-\frac{2 \sigma_{\mathrm{p}}}{\omega_{0}}=-\frac{\Delta \omega}{\omega_{0}}=\frac{1}{\mathrm{Q}}
$$

Indeed, $\Phi$ is related to the selectivity (i.e. the width $\Delta \omega$ of the peak of resonance (figure 4-a) divided by the pulsation of resonance $\omega_{0}$ ) which is equal to $1 / \mathrm{Q}$. Thus, a high $\mathrm{Q}$ corresponds to a low $\Phi$ and the associated pole is close to the vertical axis.

Finally, instead of using the Cartesian representation of natural poles in $\left\{\sigma_{p} ; \omega_{p}\right\}$, it is interesting to use this new representation in $\left\{\omega_{0} ; Q\right\}$.

We apply now this resonator point of view to the scattering transfer function $\mathrm{H}(\mathrm{s})$ of a radar target, which can be expressed as a sum of transfer functions $A_{m}(s)$ (equation (5)) of elementary resonators $\left\{\omega_{0, \mathrm{~m}} ; \mathrm{Q}_{\mathrm{m}}\right\}$.

For the $\mathrm{m}^{\text {th }}$ singularity $\left(\mathrm{s}_{\mathrm{m}}=\sigma_{\mathrm{m}}+\mathrm{j} \omega_{\mathrm{m}}\right)$, the natural pulsation of resonance, $\omega_{0, \mathrm{~m}}$, and the quality factor, $\mathrm{Q}_{\mathrm{m}}$, are respectively given by

$$
\omega_{0, \mathrm{~m}}=\left|\mathrm{s}_{\mathrm{m}}\right| \quad \mathrm{Q}_{\mathrm{m}}=-\frac{\omega_{0, \mathrm{~m}}}{2 \sigma_{\mathrm{m}}}
$$

As an example, natural poles of the sphere and the dipole, plotted in Cartesian coordinates $\left\{\sigma_{\mathrm{m}} ; \omega_{\mathrm{m}}\right\}$ in figure 2 , are now plotted in $\left\{\omega_{0, \mathrm{~m}} ; \mathrm{Q}_{\mathrm{m}}\right\}$ representation in figure 5 .

\subsection{Use of resonance parameters to characterize objects}

Resonance parameters can be used to characterize objects. Indeed, the representation of natural poles in $\left\{\omega_{0, m} ; Q_{m}\right\}$ provides an efficient means for that because it better separates information than the usual Cartesian mapping in the complex plane: $\omega_{0, \mathrm{~m}}$ gives some indications on dimensions of the target and $Q_{m}$ brings out the resonance behaviour of targets. Moreover, $\mathrm{Q}_{\mathrm{m}}$ is a discriminatory of the aspect ratio of targets and consequently gives some indications on the general shape of targets. We now investigate separately each resonance parameter, $\omega_{0, m}$ and $Q_{m}$, for both canonical examples, the sphere and the dipole (figure 5).

\subsubsection{Natural pulsation of resonance $\omega_{0}$}

First, we compare the natural pulsation of resonance of the fundamental pole of a target, $\omega_{0,1}$, to the natural pulsation of resonance, $\left(\omega_{0}\right)_{\mathrm{P}}$, of a creeping wave travelling on the surface of this object along a given perimeter $\mathrm{P}$ with a wavelength equal to this perimeter (Chauveau, 2007-b)

$$
\left(\omega_{0}\right)_{\mathrm{P}} \approx \frac{2 \Pi \mathrm{c}}{\mathrm{P}}
$$

with $\mathrm{c}$, the speed of light in vacuum, and $\mathrm{P}$, the path travelled by the wave over the surface. 


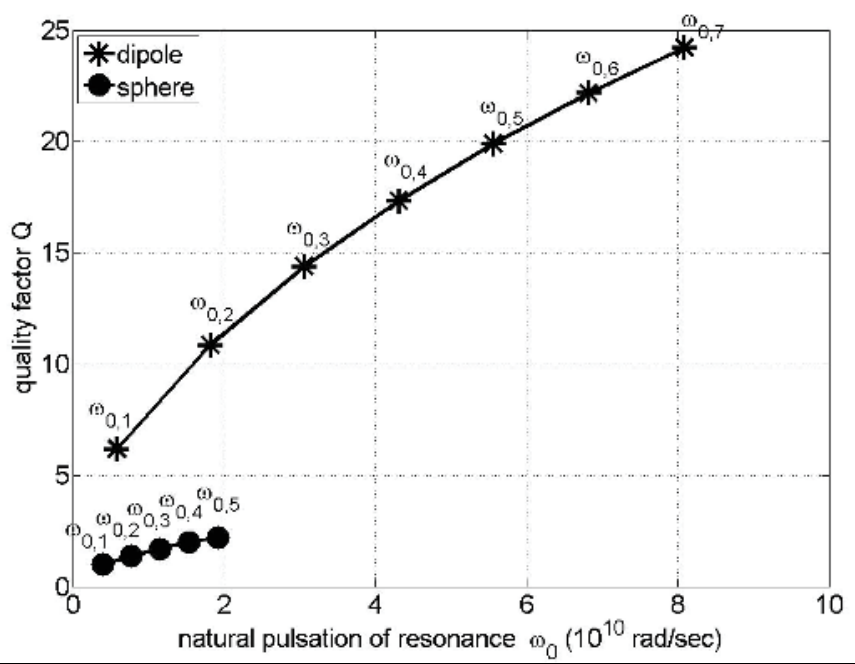

Fig. 5. Natural poles of the sphere and the dipole in the $\left\{\omega_{0, m} ; Q_{m}\right\}$ representation.

For the sphere, the perimeter is $\mathrm{P}=\Pi \mathrm{D}$. With a diameter $\mathrm{D}=0.15 \mathrm{~m}$, we get $\mathrm{P}=0.471 \mathrm{~m}$ and, from equation (12), $\left(\omega_{0}\right)_{\mathrm{P}}=4.00210^{9} \mathrm{rad} / \mathrm{sec}$, to be compared to $\omega_{0,1}=4.00110^{9} \mathrm{rad} / \mathrm{sec}$, while $\omega_{1}=3.46510^{9} \mathrm{rad} / \mathrm{sec}$. We can notice that $\left(\omega_{0}\right)_{\mathrm{P}}$ nearly equals $\omega_{0,1}$, the modulus of $\mathrm{s}_{1}$, and differs from $\omega_{1}$, the imaginary part of $s_{1}$. Indeed, the representation in $\left\{\omega_{0, m} ; Q_{m}\right\}$ permits to show that this external resonance belongs to the creeping wave.

For the dipole, with $\mathrm{L}=0.15 \mathrm{~m}$ and $\mathrm{D}=0.001 \mathrm{~m}$, we get $\mathrm{P}=2(\mathrm{~L}+\mathrm{D}) \approx 2 \mathrm{~L}=0.30 \mathrm{~m}$. From (Harrington, 1961), (Kinnon, 1999), the natural pulsation of resonance of the dipole, $\left(\omega_{0}\right)_{\mathrm{d}}$, is given by $\left(\omega_{0}\right)_{\mathrm{d}}=0.95\left(\omega_{0}\right)_{\mathrm{P}}$, with $\left(\omega_{0}\right) \mathrm{P}$ given by equation $(12)$, thus $\left(\omega_{0}\right)_{\mathrm{d}}=5.96910^{9}$ $\mathrm{rad} / \mathrm{sec}$, to be compared to $\omega_{0,1}=5.82610^{9} \mathrm{rad} / \mathrm{sec}$, while $\omega_{1}=5.80710^{9} \mathrm{rad} / \mathrm{sec}$. We notice here that the natural pulsation $\omega_{0,1}$ and the damped pulsation $\omega_{1}$ are nearly equal as can be seen from equation (9) because the dipole is a very resonant object with high Q-factor $\left(\mathrm{Q}_{1} \approx\right.$ 6.19 for the fundamental pole $\mathrm{s}_{1}$ ).

Harmonic pulsations of the fundamental pulsation of resonance follow the same behaviour. For the sphere, $\omega_{0, \mathrm{~m}}=\mathrm{m} \omega_{0,1}(\mathrm{~m}=1,2, \ldots)$, while for the dipole only odd harmonic pulsations are present, that is $\omega_{0, m}=(2 \mathrm{~m}-1) \omega_{0,1}(\mathrm{~m}=1,2, \ldots)$ (Harrington, 1961), (Kinnon, 1999).

\subsubsection{Quality factor $Q$}

Secondly, we examine the $Q$ parameter: we can see that the conducting sphere is a weakly resonant target $\left(\mathrm{Q}_{1} \approx 1\right.$ for the fundamental pole $\left.\mathrm{s}_{1}\right)$. Indeed, it has been shown (Long, 1994) (Moser \& Überall, 1983), (Moffatt \& Mains, 1975\} that more a conducting object is voluminous as the sphere, less it is resonant (low Q), because more the object surface is large relatively to its dimension, more losses on the surface are important. Moreover, this low resonant behaviour can also come from the degeneracy phenomenon of the external poles, due to geometrical symmetries of the sphere (Long, 1994), (Rothwell \& Cloud, 1999). On the contrary, the dipole is a very resonant object, with a high quality factor $\left(Q_{1} \approx 6.19\right.$ for the fundamental pole $\mathrm{s}_{1}$ ). Consequently, the quality factor can give information on the aspect ratio of the target (Chauveau, 2007-b). 
In this general presentation of resonance parameters, we only considered closed objects so as to simplify our purpose. Thus, in this case, we only get external resonances. But, we now intend to focus on the resonance behaviour of targets with apertures, which can give access to internal resonances. First, we choose the simple example of an open rectangular cavity (section 3). Next, we present a more realistic example in the case of an aircraft with airintakes (section 4).

\section{Study of a PC rectangular open cavity}

When illuminated in a suitable frequency band, an aperture in a radar target body can give access to high-Q internal resonances. Hence the use of natural frequencies of resonance, mainly internal ones, is a relevant basis for open targets identification. In this way, Rothwell and Cloud (Rothwell \& Cloud, 1999) calculate analytically natural frequencies of a canonical target: a hollow perfectly conducting sphere with a circular aperture. Their study presents an interesting behaviour of poles in the complex plane depending on whether the poles originate from internal or external sphere resonances. However, they conclude that the sphere is probably not a good candidate for target identification studies, because of its modal degeneracy. Our approach is different: we intend to show, from the RCS of a target, how resonance parameters depend on its dimensions. For this purpose, we choose to study a perfectly conducting rectangular cavity with a rectangular aperture. On one hand, this example is a more realistic model of air-intake than a spherical cavity; moreover its resonance pulsations are well-known. On the other hand, the search of poles no longer uses an analytical method but a numerical one, based on SEM and therefore applicable to any target and not only to canonical ones. However, the SEM method extracts the whole set of poles, without separating internal and external poles. Consequently, our main objective is to show how we can discriminate the two origins of these poles: external poles corresponding to creeping waves on the surface of the target and internal poles corresponding to internal cavity waves. For this purpose, we first compare poles of the rectangular cavity with those of a closed rectangular box of the same size (section 3.2). Next, we study the variation of these poles with dimensions of the cavity (section 3.3).

\subsection{Parameters of the PC rectangular cavity}

The studied rectangular cavity is open on one side with a centered slot (figure 6). Its characteristic dimensions are given in table 1: height $\mathrm{h}$, width $\mathrm{w}$, depth $\mathrm{d}$, and slot height $\mathrm{s}$. The configuration of the excitation is

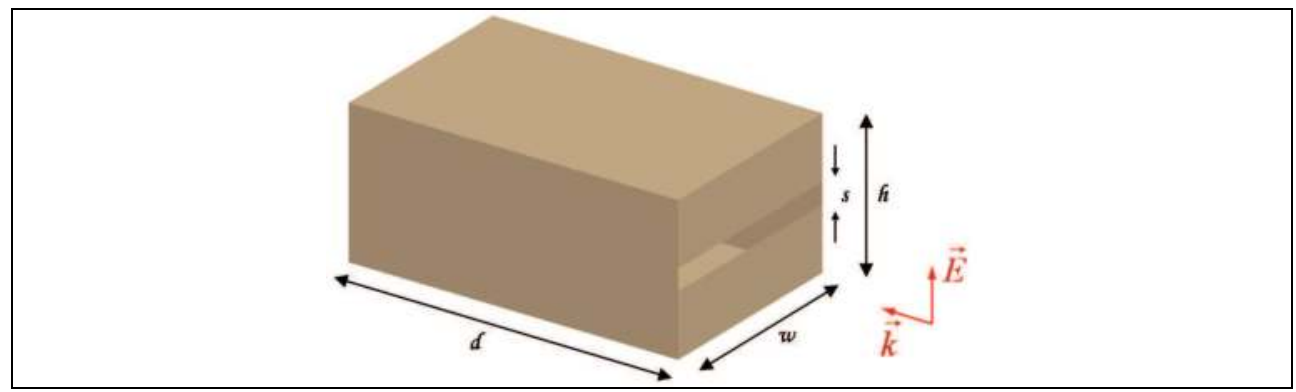

Fig. 6. Geometry of the rectangular cavity (slot centered in the front wall). 
- frequency band of investigation: [50MHz;685MHz]

- excitation: electric field $\vec{E}$ parallel to the vertical direction $h$ and direction of propagation $\overrightarrow{\mathrm{k}}$ perpendicular to the aperture plane $(\mathrm{w}, \mathrm{h})$

- monostatic study

- target (inside and outside) in vacuum

\begin{tabular}{|c|c|}
\hline dimensions $(\mathrm{m})$ & theoretical resonance pulsations $\left(10^{9} \mathrm{rad} / \mathrm{sec}\right)$ \\
\hline $\mathrm{h}=0.35$ & internal cavity modes \\
$\mathrm{w}=0.50$ & $\left(\omega_{0}\right)_{011}=2.22$ \\
$\mathrm{~d}=0.80$ & $\left(\omega_{0}\right)_{012}=3.02$ \\
$\mathrm{~s}=0.05$ & $\left(\omega_{0}\right)_{013}=4.00$ \\
\hline & external modes \\
$\mathrm{P}_{\mathrm{sw}}=2(\mathrm{w}+\mathrm{s})=1.10$ & $\left(\omega_{0}\right)_{\mathrm{sw}}=1.71$ \\
$\mathrm{P}_{\mathrm{hw}}=2(\mathrm{~h}+\mathrm{w})=1.70$ & $\left(\omega_{0}\right)_{\mathrm{hw}}=1.11$ \\
$\mathrm{P}_{\mathrm{hd}}=2(\mathrm{~h}+\mathrm{d})=2.30$ & $\left(\omega_{0}\right)_{\mathrm{hd}}=0.82$ \\
$\mathrm{P}_{\mathrm{wd}}=2(\mathrm{w}+\mathrm{d})=2.60$ & $\left(\omega_{0}\right)_{\mathrm{wd}}=0.72$ \\
\hline
\end{tabular}

Table 1. Characteristic dimensions of the cavity and theoretical natural pulsations of resonance.

The internal modes of a closed rectangular cavity have natural pulsations of resonance given by equation (13) (Harrington, 1961)

$$
\left(\omega_{0}\right)_{\mathrm{mnp}}=\frac{\Pi}{(\varepsilon \mu)^{1 / 2}}\left[\left(\frac{\mathrm{m}}{\mathrm{h}}\right)^{2}+\left(\frac{\mathrm{n}}{\mathrm{w}}\right)^{2}+\left(\frac{\mathrm{p}}{\mathrm{d}}\right)^{2}\right]
$$

where $\varepsilon$ and $\mu$ are respectively the permittivity and the permeability of the medium inside the cavity; and with $\mathrm{m}=0,1,2, \ldots ; \mathrm{n}=0,1,2, \ldots ; \mathrm{p}=1,2,3, \ldots ; \mathrm{m}=\mathrm{n}=0$ being excepted. For an open cavity, the presence of the slot slightly perturbs the resonant pulsation $\omega_{0}$ and makes the Q-factor finite, corresponding to a non-zero damping factor, $\sigma_{\mathrm{m}}$.

In the frequency band of investigation, with such dimensions of the target and such orientations of the electric field $\overrightarrow{\mathrm{E}}$ and the slot, there are only three possible cavity modes, $\left(\omega_{0}\right)_{011},\left(\omega_{0}\right)_{012}$ and $\left(\omega_{0}\right)_{013}$, satisfying equation (13). Their values are given in table 1 for corresponding dimensions and $\varepsilon=\varepsilon_{0}$ and $\mu=\mu_{0}$ for vacuum.

The external modes of resonance are waves creeping on the outside surface of the PC cavity. There are four fundamental natural pulsations, given by equation (12), which correspond to each perimeter, $\mathrm{P}_{\mathrm{sw}}, \mathrm{P}_{\mathrm{hw}}, \mathrm{P}_{\mathrm{hd}}$ and $\mathrm{P}_{\mathrm{wd}}$. Values of these perimeters and their corresponding fundamental natural pulsations are given in table 1 . Moreover, for each characteristic dimension, it is possible to find further harmonic natural pulsations.

\subsection{Comparison with a PC closed rectangular box}

In order to distinguish internal and external resonances, we propose to compare the PC open rectangular cavity with the PC closed rectangular box of same dimensions without the slot, both objects being studied with the same excitation configuration. The box being closed, internal resonances cannot be excited from an outside illumination, hence only external resonances are present. 
Figure 7 compares the modulus of the scattered-field transfer function $|H(\omega)|$ for the open cavity (solid line) and the PC closed box (dashed line). The cavity response presents narrow peaks of resonance occurring at expected resonance pulsations of each cavity mode, $\left(\omega_{0}\right)_{011}$, $\left(\omega_{0}\right)_{012}$ and $\left(\omega_{0}\right)_{013}$. We can see another peak of resonance occurring near the natural pulsation corresponding to the resonance of the slot $\left(\omega_{0}\right)_{\text {sw }}$. Wider peaks are also present corresponding to lower quality of resonance. Indeed, these wider peaks also exist for the box response.

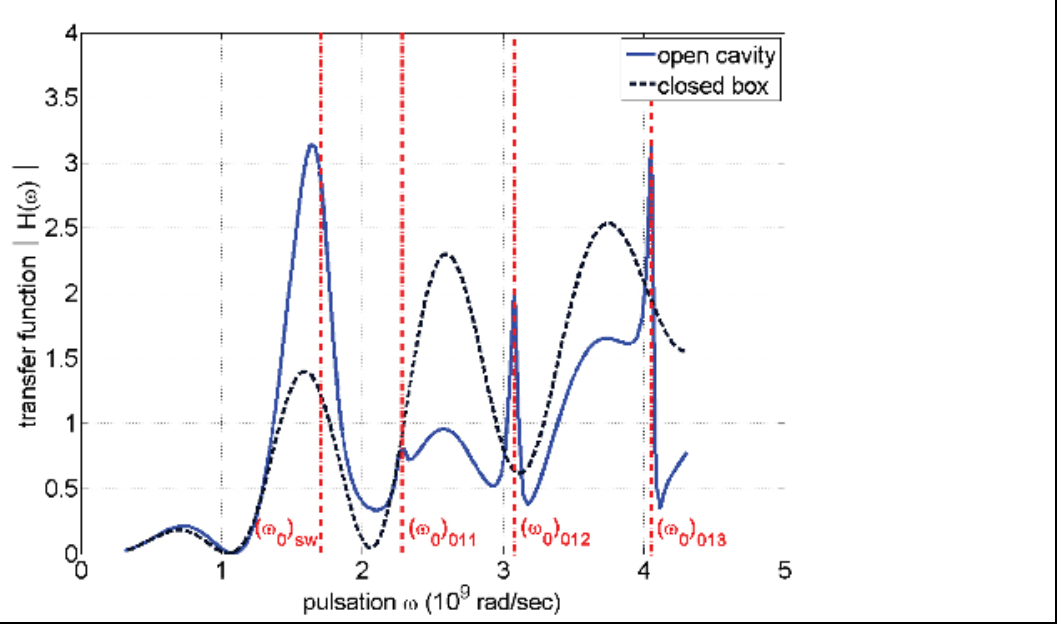

Fig. 7. Comparison between $|\mathrm{H}(\omega)|$ of the open cavity and the closed box.

Figures 8 and 9 compare the cavity and the box using both representations of resonance parameters (see section 2), respectively the Cartesian mapping of natural poles in the complex plane $\left\{\sigma_{\mathrm{m}} ; \omega_{\mathrm{m}}\right\}$ and the quality factor as a function of the natural pulsation of resonance $\left\{\omega_{0, \mathrm{~m}} ; \mathrm{Q}_{\mathrm{m}}\right\}$. First, we examine poles existing only for the open cavity, i.e. those numbered ' 1 ', ' 2 ', ' 3 ' and ' 4 '. We can see that resonance pulsations of poles of the open cavity numbered ' '1', '2' and '3' almost correspond to theoretical pulsations of the closed cavity modes, $\left(\omega_{0}\right)_{011},\left(\omega_{0}\right)_{012}$ and $\left(\omega_{0}\right)_{013}$ (see table 1 and figure 9$)$. Indeed, these three pulsations of resonance coincide with the narrowest resonance peaks of the open cavity response (figure 7). Accordingly, these three poles have a very low damping coefficient $\left|\sigma_{\mathrm{m}}\right|$ (figure 8 ) and correspond to a high quality factor $Q_{m}$ (figure 9). About the pole '4', its resonance pulsation corresponds to the resonance pulsation $\left(\omega_{0}\right)_{\mathrm{sw}}$ of the slot with $\mathrm{P}_{\mathrm{sw}}$ in equation (12). This pole has a higher damping coefficient $\left|\sigma_{\mathrm{m}}\right|$ and a lower quality factor $Q_{\mathrm{m}}$ than poles ' 1 ', ' 2 ' and ' 3 '. Indeed, the peak of resonance occurring at the resonance pulsation of the slot $\left(\omega_{0}\right)_{s w}$ is wider than previous peaks corresponding to internal resonances ' 1 ', ' 2 ' and ' 3 '.

Concerning natural poles '5', ' 6 ', '7' and ' 8 ' of the open cavity, we can see that they are very close to natural poles of the box. Consequently, we can state that these four poles correspond to creeping waves on the outside surface of the perfectly conducting cavity. Following equation (12), these natural poles depend on various perimeters of the target given in table 1 . For example, the pole numbered ' 5 ' can correspond to both characteristic perimeters $\mathrm{P}_{\mathrm{hd}}$ or $\mathrm{P}_{\mathrm{hw}}$. The three other poles appear to correspond to harmonic poles which mainly depend on dimensions $h$ and $d$. 


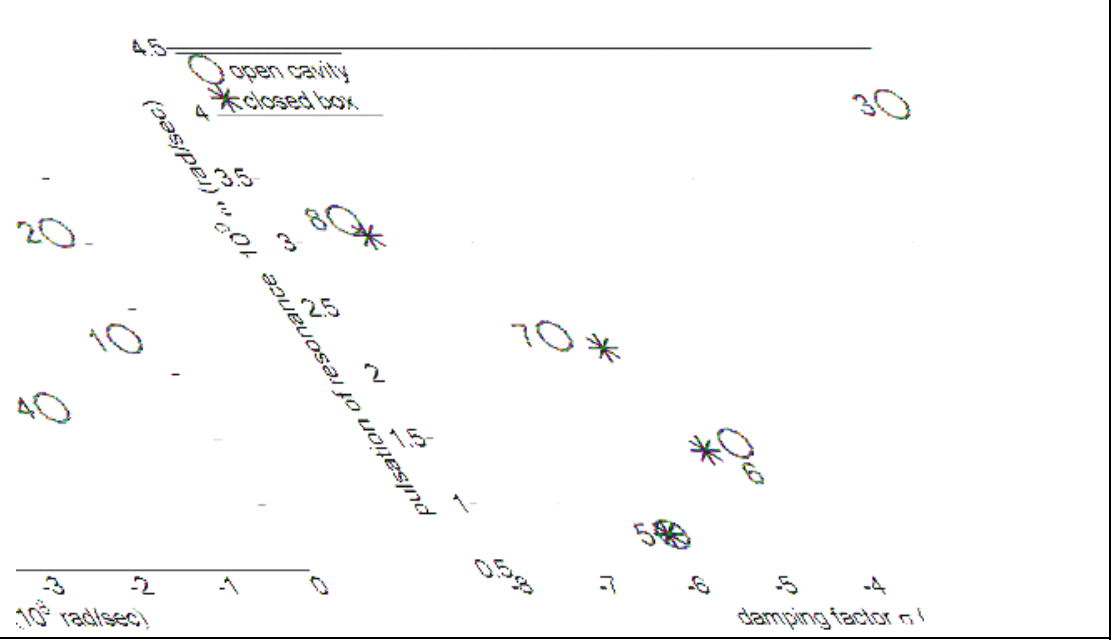

Fig. 8. Comparison of the mapping of poles $\left\{\sigma_{\mathrm{m}} ; \omega_{\mathrm{m}}\right\}$ of the open cavity and the closed box.

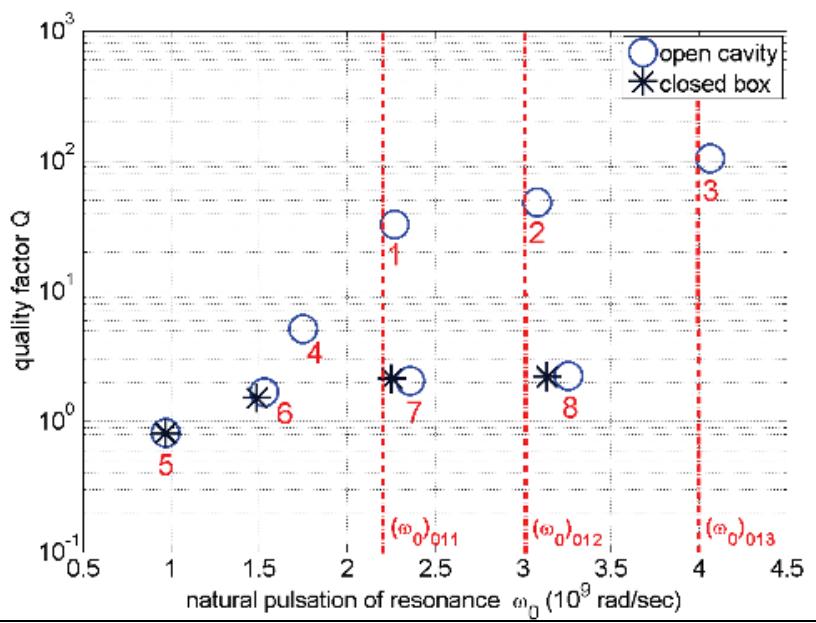

Fig. 9. Comparison of resonance parameters in $\left\{\omega_{0, m} ; Q_{m}\right\}$ representation of the open cavity and the closed box.

\subsection{Effect of dimensions of the rectangular cavity}

In (Chauveau, 2009), we vary each characteristic dimensions of the open cavity and we examine how natural poles move. To quantify the dependence of the natural pulsation of resonance $\omega_{0}$ on each dimension, we compute the variation of $\omega_{0}$ with each dimension of the cavity $\left(\mathrm{y}=\mathrm{h}, \mathrm{w}, \mathrm{d}\right.$ or s), i.e. $\mathrm{d} \omega_{0} / \mathrm{dy}$, relatively to $\omega_{0}$. Results obtained in (Chauveau, 2009) are given in table 2 : the mean of the absolute value of this variation: $\left\langle\left|\mathrm{d} \omega_{0} / \mathrm{dy}\right| / \omega_{0}\right\rangle$ for each dimension of the cavity and each pole. We consider that the natural pulsation of resonance of a pole appreciably depends on a dimension of the cavity when this relative variation is significant (noted in bold in table 2). 
Poles numbered ' 1 ', ' 2 ' and ' 3 ' are internal resonances corresponding to the first modes of the cavity. Indeed, their pulsations of resonance only depend on dimensions $\mathrm{w}$ and $\mathrm{d}$ because of the orientation of the incident electric field $\vec{E}$ which points to the direction of $h$ (figure 6 ) involving $\mathrm{m}=0$ in equation (13).

The pole numbered ' 4 ' corresponds to the resonance of the slot and consequently is an external resonance. $\omega_{0}$ depends strongly on the slot width $\mathrm{w}$ and to a smaller degree on the slot height s.

In the same way, poles numbered ' 6 ', '7' and ' 8 ' are external resonances with a similar behavior with the variation of dimensions of the cavity: their pulsations of resonance are strongly affected by the variation of dimensions $h$ and $d$. Thus, we deduce that these poles depend on the perimeter $P_{\text {hd }}$ of the cavity. In fact, these three poles are harmonic poles corresponding to the perimeter $\mathrm{P}_{\mathrm{hd}}$. Moreover the pole ' 7 ' is affected by the slot, its pulsation of resonance slightly varying as a function of $\mathrm{s}$.

The pole numbered ' 5 ' is an external resonance, with $\omega_{0}$ mainly depending on the dimension $\mathrm{h}$, but also on $\mathrm{w}$ and $\mathrm{d}$. Consequently, we cannot determine which perimeter is associated to this pole.

Anyway, the four poles numbered '5', '6', '7' and '8', due to external creeping waves on the surface of the cavity, are very close to those of the perfectly conducting box with same dimensions, even if they are modified by the slot.

Concerning the quality of resonance, the Q-factor of internal cavity modes, ' 1 ', '2' and ' 3 ' decreases when the slot height, s, increases, anyway, $Q$ always remains higher than $Q$ of external poles, '4', '5', '6', '7' and '8' (Chauveau, 2009). Indeed, radiating losses are much stronger for external resonances than for internal resonances, consequently, internal resonances are predominant.

\begin{tabular}{|c|c|c|c|c|}
\hline pole dimension & $\mathrm{h}$ & $\mathrm{w}$ & $\mathrm{d}$ & $\mathrm{S}$ \\
\hline 1 & 0.05 & $\mathbf{1 . 1 4}$ & $\mathbf{0 . 3 5}$ & 0.15 \\
\hline 2 & 0.05 & $\mathbf{0 . 6 2}$ & $\mathbf{0 . 7 0}$ & 0.29 \\
\hline 3 & 0.06 & $\mathbf{0 . 3 5}$ & $\mathbf{0 . 8 9}$ & 0.25 \\
\hline 4 & 0.02 & $\mathbf{1 . 7 2}$ & 0.04 & $\mathbf{0 . 6 0}$ \\
\hline 5 & $\mathbf{1 . 2 9}$ & $\mathbf{0 . 5 1}$ & $\mathbf{0 . 4 4}$ & 0.06 \\
\hline 6 & $\mathbf{1 . 1 0}$ & 0.06 & $\mathbf{0 . 7 3}$ & 0.08 \\
\hline 7 & $\mathbf{0 . 7 4}$ & 0.15 & $\mathbf{0 . 7 5}$ & $\mathbf{0 . 4 6}$ \\
\hline 8 & $\mathbf{0 . 7 9}$ & 0.11 & $\mathbf{1 . 0 3}$ & 0.19 \\
\hline
\end{tabular}

Table 2. Relative variation of $\omega_{0}$ with dimensions of the cavity $<\left|d \omega_{0} / d y\right| / \omega_{0}>$ in $\left.m^{-1}\right)$.

\section{Application to air-intakes of a simulated aircraft}

We have shown in section 3 that resonances of a PC open object (a rectangular cavity) have two origins: external resonances corresponding to external surface creeping waves and internal resonances corresponding to internal cavity waves. Because of their high Q-factor, internal resonances are predominant, and consequently, they are more easily extracted. In this section, we propose to use this property in order to characterize a simulated aircraft with air-intakes. 
A complex shape target as an aircraft can often be modelled as a combination of canonical objects (figure 10-a), with resonances corresponding as well to canonical objects (here: cylinder, cone, three triangular wings and two cylindrical cavities) as structures created by the assembly of these canonical objects (for instance: dihedral created by the junction between each wing and the cylinder) (Chauveau, 2007-b). Indeed, air-intakes of an aircraft are cavities which can exhibit strong resonances for suitable frequency bands. Thus, we propose to use their internal resonance parameters to characterize aircrafts.

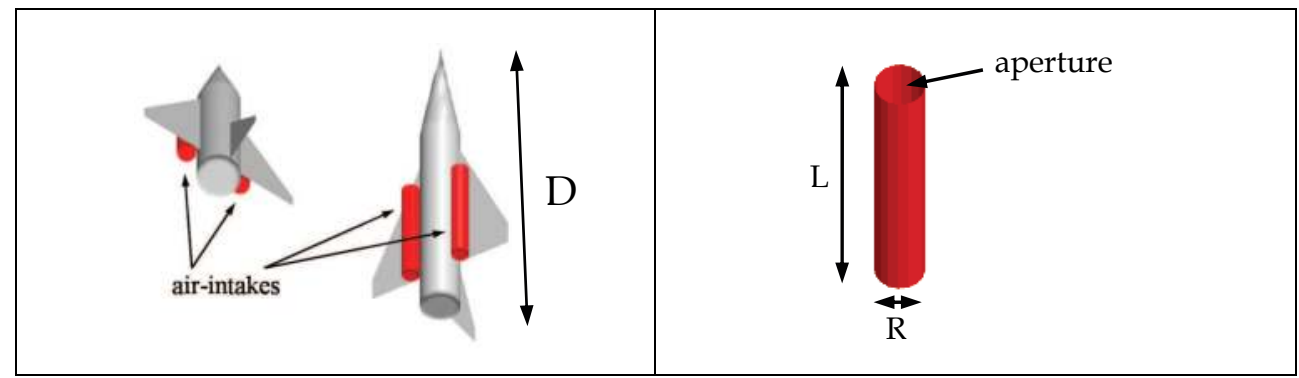

Fig. 10. Simulated aircraft with air-intakes (a) and open cylindrical cavity (b).

We first study the PC cylindrical open cavity alone (figure 10-b). This cavity has a length $\mathrm{L}=0.5 \mathrm{~m}$ and a radius $\mathrm{R}=0.04 \mathrm{~m}$, it is open on one side and it is studied in free space in the pulsation range [1.2 $\left.10^{10} \mathrm{rad} / \mathrm{sec} ; 1.810^{10} \mathrm{rad} / \mathrm{sec}\right]$. We choose this pulsation range in order to include resonance pulsations corresponding to the first modes of the cavity. Figure 11 presents extracted resonance parameters of the cylindrical cavity, in both representations. We can see that we have a branch of 5 poles with low damping factor $\sigma$ and high Q-value $\left(\mathrm{Q}_{1} \approx 250\right)$.

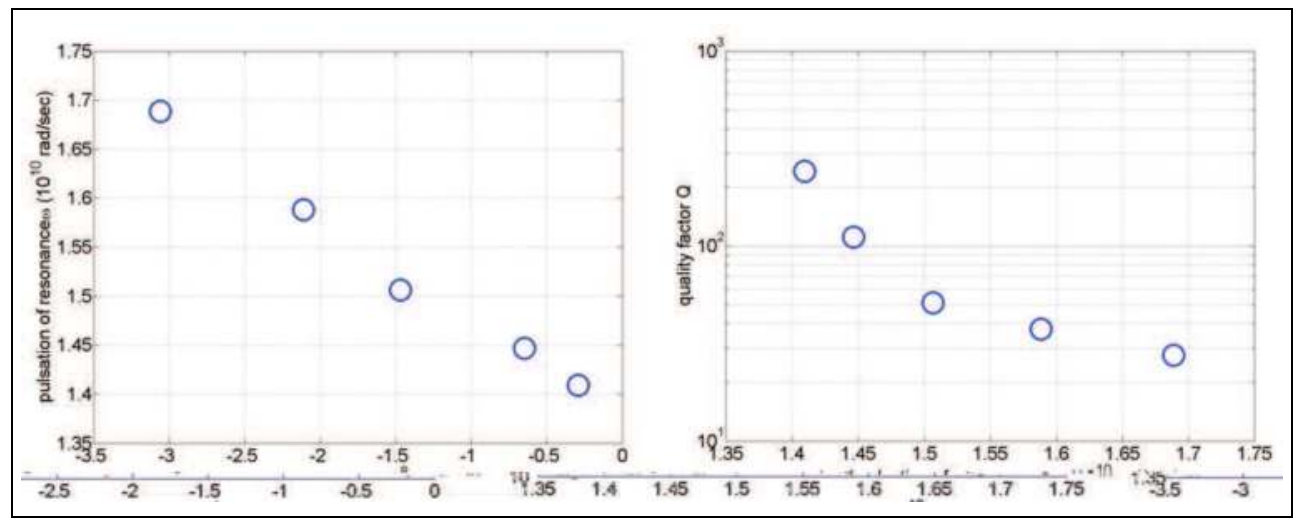

Fig. 11. Poles of the open cylindrical cavity: $\left\{\sigma_{\mathrm{m}} ; \omega_{\mathrm{m}}\right\}$ representation (left) and $\left\{\omega_{0, \mathrm{~m}} ; \mathrm{Q}_{\mathrm{m}}\right\}$ representation (right).

In order to verify that these poles correspond to internal modes of the cavity, we calculate the natural pulsation of resonance of a closed cylindrical cavity of same dimensions, $\mathrm{L}$ and R, with equation (14) (Harrington, 1961) 


$$
\left(\omega_{\mathrm{r}}\right)_{\mathrm{mnp}}=\frac{\mathrm{c}}{\mathrm{R} \sqrt{\varepsilon}} \sqrt{\mathrm{x}_{\mathrm{mn}}^{2}+\left(\frac{\mathrm{p} \Pi \mathrm{R}}{\mathrm{L}}\right)^{2}}
$$

where $\varepsilon$ is the permittivity of the medium inside the cavity; $x_{m n}$ are ordered zeros of Bessel functions $\mathrm{J}_{\mathrm{m}}(\mathrm{x})$ given in (Harrington, 1961).

In the frequency band of investigation and with such dimensions of the target, only 5 cavity modes satisfy equation (14): $\mathrm{m}=1 ; \mathrm{n}=1 ; \mathrm{p}=[1: 5]$. In table 3 , their values are compared with natural pulsations of resonance $\omega_{0, \mathrm{~m}}$ (noted $\omega_{\text {open_cavity }}$ ) extracted from the transfer function $\mathrm{H}(\omega)$ of the cylindrical open cavity. We can see that resonance pulsations $\omega_{\text {open_cavity }}$ of extracted poles of the open cavity are nearly equal to theoretical resonance pulsations $\omega_{\text {closed_cavity }}$ of the closed cavity. Thus, these extracted poles actually correspond to internal resonances.

\begin{tabular}{|c|c|c|c|}
\hline $\mathrm{p}$ & $\begin{array}{c}\omega_{\text {closed_cavity }} \\
\left(10^{10} \mathrm{rad} / \mathrm{sec}\right)\end{array}$ & $\begin{array}{c}\omega_{\text {open_cavity }} \\
\left(10^{10} \mathrm{rad} / \mathrm{sec}\right)\end{array}$ & $\begin{array}{c}\omega_{\text {aircraft }} \\
\left(10^{10} \mathrm{rad} / \mathrm{sec}\right)\end{array}$ \\
\hline 1 & 1.39 & 1.41 & 1.42 \\
\hline 2 & 1.43 & 1.45 & 1.43 \\
\hline 3 & 1.49 & 1.51 & 1.52 \\
\hline 4 & 1.57 & 1.59 & $/$ \\
\hline 5 & 1.67 & 1.69 & $/$ \\
\hline
\end{tabular}

Table 3. Comparison of calculated resonance pulsations of the closed cavity $\omega_{\text {closed_cavity, }}$ extracted resonance pulsations of the open cavity $\omega_{\text {open_cavity }}$ and extracted resonance pulsations of the aircraft $\omega_{\text {aircraft }}$.

We now compare the previous open cavity alone (figure 10-b) with the simulated aircraft (figure 10-a), in the same configuration (free space, pulsation range, excitation ...). The aircraft has a characteristic dimension $\mathrm{D}=1.5 \mathrm{~m}$ and both air-intakes have the same dimensions as the open cavity.

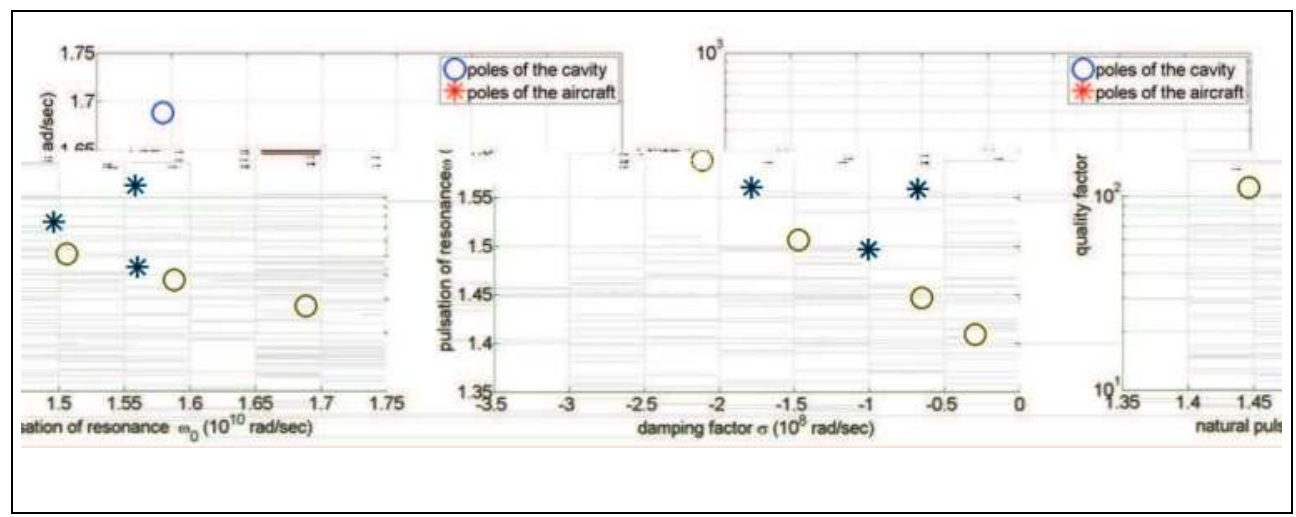

Fig. 12. Comparison of poles of the open cylindrical cavity and the simulated aircraft in wideband response: $\left\{\sigma_{\mathrm{m}} ; \omega_{\mathrm{m}}\right\}$ representation (left) and $\left\{\omega_{0, \mathrm{~m}} ; \mathrm{Q}_{\mathrm{m}}\right\}$ representation (right).

We are interested only in internal resonances of air-intakes, that is why we choose the pulsation range $\left[1.210^{10} \mathrm{rad} / \mathrm{sec} ; 1.810^{10} \mathrm{rad} / \mathrm{sec}\right]$, corresponding to the 5 first modes of the 
cavity. In figure 12, we can see that only 3 poles are extracted for the aircraft and these poles cannot be associated with poles of the cavity alone.

In order to intend to retrieve more precisely poles of the open cavity, we calculate poles of the aircraft in narrow frequency bands. Indeed, in (Chauveau, 2007-c), we show the possibility to extract natural poles one-by-one in tuning narrow frequency bands to frequencies of wanted poles. Thus, we apply this method of poles extraction to the simulated aircraft in order to find the three first poles of the open cavity. We respectively search the first pole in the pulsation range $\left[1.3510^{10} \mathrm{rad} / \mathrm{sec} ; 1.4410^{10} \mathrm{rad} / \mathrm{sec}\right]$, the second pole in $\left[1.4010^{10} \mathrm{rad} / \mathrm{sec} ; 1.4610^{10} \mathrm{rad} / \mathrm{sec}\right]$ and the third pole in $\left[1.4710^{10} \mathrm{rad} / \mathrm{sec} ; 1.5510^{10}\right.$ $\mathrm{rad} / \mathrm{sec}$. We can see in figure 13 and in table 3 that the pulsations of these poles are now correctly extracted. This shows the advantage of the narrow band extraction of poles.

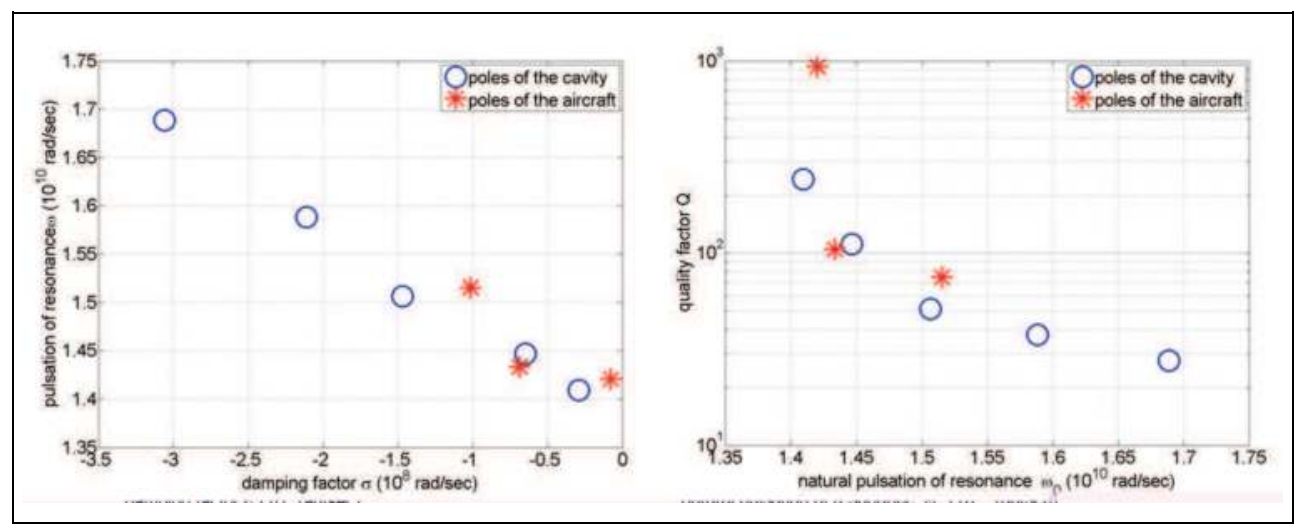

Fig. 13. Comparison of poles of the open cylindrical cavity and the simulated aircraft in narrow band response: $\left\{\sigma_{\mathrm{m}} ; \omega_{\mathrm{m}}\right\}$ representation (left) and $\left\{\omega_{0, \mathrm{~m}} ; \mathrm{Q}_{\mathrm{m}}\right\}$ representation (right).

\section{Conclusion and perspectives}

In this chapter, we have first presented how to extract natural poles from the simulated transfer function of a target and how to use them for identification purposes. We have introduced a new representation of poles with quality factor $Q$ and natural pulsation of resonance $\omega_{0}$ in order to better separate information: the $Q$ parameter permits to bring out clearly the resonance behaviour of targets $(Q$ is a discriminatory of the aspect ratio of targets), and the natural pulsation of resonance $\omega_{0}$ depends on dimensions of targets. Next, we have extended our study to resonances of targets with apertures. The simple example of a PC rectangular open cavity has permitted to show how resonance parameters depend on object dimensions and how internal and external resonances can be distinguished, by comparison of poles of the open cavity and the closed box. Internal resonances having a lower damping coefficient $\left|\sigma_{\mathrm{m}}\right|$ than external resonances, they have a higher quality of resonance $Q_{m}$, and can therefore be more easily extracted. That is why, we have used this interesting property of internal resonances in order to identify an aircraft with air-intakes. Thus, we have shown that the use of selective narrow frequency bands permits a better extraction of poles in the case of complex objects, as aircrafts with air-intakes. 


\section{References}

Adve, R.S.; Sarkar, T.K.; Rao, S.M.; Miller, E.K. \& Pflug, D.R. (1997). Application of the Cauchy Method for Extrapolating/Interpolating Narrow-Band System Responses. IEEE Transaction on Microwave Theory and Techniques, Vol. 45, No. 5, May 1997, pp. 837-845

Anastassiu, H.T. (2003). A review of electromagnetic scattering analysis for inlets, cavities and open ducts. IEEE Antennas and Propagation Magazine, vol. 45, No. 6, 2003, pp. $27-40$

Baum, C.E. (1976). The Singularity Expansion Method, In: Transient Electromagnetic Field, L.B. Felsen (Ed. New York: Springer - Verlag) pp. 129-179

Baum, C.E.; Rothwell, E.J.; Chen, K.M. \& Nyquist, D.P. (1991). The Singularity Expansion Method and Its Application to Target Identification. Proceedings of the IEEE, Vol. 79, No. 10, October 1991, pp. 1481-1492

Berni, A.J. (1975). Target Identification by Natural Resonance Estimation. IEEE Transaction on Aerospace Electronic Systems, Vol. 11, No. 2, 1975, pp. 147-154

Cauchy, A.L. (1821). Sur la formule de Lagrange relative à l'interpolation. Analyse algébrique, Paris, 1821.

Chauveau, J.; de Beaucoudrey, N.; \& Saillard, J. (2007-a). Selection of Contributing Natural Poles for the Characterization of Perfectly Conducting Targets in Resonance Region. IEEE Transaction on Antennas and Propagation, Vol. 55, No. 9, September 2007, pp. 2610-2617

Chauveau, J.; de Beaucoudrey, N.; \& Saillard, J. (2007-b). Characterization of Perfectly Conducting Targets in Resonance Domain with their Quality of Resonance. Progress In Electromagnetic Research, Vol. 74, 2007, pp. 69-84

Chauveau, J.; de Beaucoudrey, N.; \& Saillard, J. (2007-c). Determination of Resonance Poles of Radar Targets in Narrow Frequency Bands. EuMW/Eurad, Germany, Munich, October 2007.

Chauveau, J.; de Beaucoudrey, N.; \& Saillard, J. (2009). Resonance behaviour of radar targets with aperture. Example of an open rectangular cavity. Submitted in IEEE Transaction on Antennas and Propagation

Chen, C-C. (1998). Electromagnetic resonances of Immersed Dielectric Spheres. IEEE Transaction on Antennas and Propagation, Vol. 46, No. 7, July 1998, pp. 1074-1083

Chen, K.M.; Nyquist, D.P.; Rothwell, E.J.; Webb, L.L. \& Drachman, B. (1986). Radar Target Discrimination by Convolution of Radar Return with Extinction-Pulses and SingleMode Extraction Signals. IEEE Transaction on Antennas and Propagation, Vol. 34, No. 7, 1986, pp. 896-904

Harrington, R.F. (1961). Time-harmonic electromagnetic fields, McGraw-Hill book company Inc., New York, 1961

Householder, A.S. (1950). On Prony's method of fitting exponential decay curves and multiple-hit survival curves. Oak RidgeNat. Lab., Oak Ridge, TN, Tech. Rep. ORNL-455, February 1950.

Hua, Y. \& Sarkar, T.K. (1991). On SVD for Estimating Generalized Eigenvalues of Singular Matrix Pencil in Noise. IEEE Transaction on Signal Processing, Vol. 39, No. 4, April 1991, pp. 892-900

Jang, S.; Choi, W.; Sarkar, T.K.; Salazar-Palma, M.; Kim, K. \& Baum, C.E. (2004). Exploiting Early Time Response Using the Fractional Fourier Transform for Analyzing 
Transient Radar Returns. IEEE Transaction on Antennas and Propagation, Vol. 52, No. 11, November 2004, pp. 3109-3121

Kennaugh, E.M. \& Moffatt, D.L. (1965). Transient and Impulse Response Approximations. Proceedings of the IEEE, Vol. 53, August 1965, pp. 893-901

Kinnon, D. (1999). Identification of Landmines Using Microwave Resonance Signatures. The University of Queensland, Thesis Report, October 1999.

Kottapalli, K.; Sarkar, T.K.; Hua Y.; Miller, E.K. \& Burke, G.J. (1991). Accurate Computation of Wide-Band Response of Electromagnetic Systems Utilizing Narrow-Band Information. IEEE Transaction on Microwave Theory and Techniques, Vol. 39, No. 4, April 1991, pp. 682-687

Kumaresan, R. (1990-a). On a frequency domain analog of Prony's method. IEEE Transaction on Acoustics, Speech, and Signal Processing, Vol. 38, January 1990, pp. 168-170

Kumaresan, R. (1990-b). Identification of Rational Transfer Function from Frequency Response Samples. IEEE Transaction on Aerospace Electronic Systems, Vol. 26, No. 6, November 1990, pp. 925-934

Li, L. \& Liang, C.H. (2004). Analysis of resonance and quality factor of antenna and scattering systems using complex frequency method combined with model-based parameter estimation. Progress In Electromagnetic Research, Vol. 46, 2004, pp. 165-188

Licul, S. (2004). Ultra-wideband antenna characterization and measurements. Ph.D. dissertation, Blacksburg, VA: Virginia Tech., 2004

Long, Y. (1994). Determination of the Natural Frequencies for Conducting Rectangular Boxes. IEEE Transaction on Antennas and Propagation, Vol. 42, No. 7, 1994, pp. 10161021.

Moffatt, D.L. \& Mains, R.K. (1975). Detection and Discrimination of radar targets. IEEE Transaction on Antennas and Propagation, Vol. 23, 1975, pp. 358-367

Moffatt, D.L. \& Shubert, K.A. (1977). Natural Resonances via Rational Approximants. IEEE Transaction on Antennas and Propagation, Vol. 25, No. 5, September 1977, pp. 657-660

Moser, P.J. \& Überall, H. (1983). Complex eigenfrequencies of axisymmetic perfectly conducting bodies: Radar spectroscopy. Proceedings of the IEEE, Vol. 71, 1983, pp. 171-172

Prony, R. (1795). Essai expérimental et analytique sur les lois de la dilatabilité de fluides élastiques et sur celles de la force expansive de la vapeur de l'alcool à différentes températures. Journal de l'École Polytechnique, vol. 1, cahier 2, 1795, p. 24-76

Rahman, M.D. A. \& Yu, K.B. (1987). Total least squares approach for frequency estimation using linear prediction. IEEE Transaction on Acoustic, Speech Signal Proceeding, Vol. 35, October 1987, pp. 1440-1454

Rothwell, E.J.; Chen, K.M. \& Nyquist, D.P. (1987). Extraction of the Natural Frequencies of a Radar Target from a Measured Response Using E-Pulse Techniques. IEEE Transaction on Antennas and Propagation, Vol. 35, No. 6, June 1987, pp. 715-720

Rothwell, E.J. \& Cloud, M.J. (1999). Natural frequencies of a conducting sphere with a circular aperture. Journal of Electromagnetic Waves and Applications, Vol. 13, 1999, pp. $729-755$

Sarkar, T.K. \& Pereira, O. (1995). Using the Matrix Pencil Method to Estimate the Parameters of a Sum of Complex Exponentials. IEEE Antennas and Propagation Magazine, Vol. 37, No. 1, February 1995, pp. 48-55 
Tesche, F. M. (1973). On the Analysis of Scattering and Antenna Problems Using the Singularity Expansion Technique. IEEE Transaction on Antennas and Propagation, Vol. 21, No. 1, January 1973, pp. 53-62

Toribio, R.; Pouliguen, P. \& Saillard, J. (2003). Identification of radar targets in resonance zone: E-Pulse techniques. Progress In Electromagnetic Research, Vol. 43, 2003, pp. 3958. 
Edited by Guy Kouemou

ISBN 978-953-307-029-2

Hard cover, 410 pages

Publisher InTech

Published online 01, January, 2010

Published in print edition January, 2010

In this book "Radar Technology", the chapters are divided into four main topic areas: Topic area 1: "Radar Systems" consists of chapters which treat whole radar systems, environment and target functional chain. Topic area 2: "Radar Applications" shows various applications of radar systems, including meteorological radars, ground penetrating radars and glaciology. Topic area 3: "Radar Functional Chain and Signal Processing" describes several aspects of the radar signal processing. From parameter extraction, target detection over tracking and classification technologies. Topic area 4: "Radar Subsystems and Components" consists of design technology of radar subsystem components like antenna design or waveform design.

\section{How to reference}

In order to correctly reference this scholarly work, feel free to copy and paste the following:

Janic Chauveau, Nicole de Beaucoudrey and Joseph Saillard (2010). Use of Resonance Parameters of AirIntakes for the Identification of Aircrafts, Radar Technology, Guy Kouemou (Ed.), ISBN: 978-953-307-029-2, InTech, Available from: http://www.intechopen.com/books/radar-technology/use-of-resonance-parameters-ofair-intakes-for-the-identification-of-aircrafts

\section{INTECH}

open science | open minds

\section{InTech Europe}

University Campus STeP Ri Slavka Krautzeka 83/A 51000 Rijeka, Croatia Phone: +385 (51) 770447

Fax: +385 (51) 686166 www.intechopen.com

\section{InTech China}

Unit 405, Office Block, Hotel Equatorial Shanghai No.65, Yan An Road (West), Shanghai, 200040, China 中国上海市延安西路65号上海国际贵都大饭店办公楼 405 单元 Phone: +86-21-62489820

Fax: $+86-21-62489821$ 
(C) 2010 The Author(s). Licensee IntechOpen. This chapter is distributed under the terms of the Creative Commons Attribution-NonCommercialShareAlike-3.0 License, which permits use, distribution and reproduction for non-commercial purposes, provided the original is properly cited and derivative works building on this content are distributed under the same license. 